\title{
PROPERTY RIGHT PROTECTION OF REPRODUCIBLE GENETIC MATERIAL
}

\author{
LeRoy Hansen and Mary Knudson
}

The duplicating of purchased materials has raised property right protection issues with copyrighted publications (with the advent of photo-copying machines); audio and video recordings; and computer software. In agriculture, genetic materials of plants and animals are duplicated through reproduction, especially with pure-line variety crops such as soybeans and wheat. The harvest of a pure-line variety is genetically similar to the parent plant. Thus, a farmer's harvest is a copy, but not identical as some loss in genetic purity occurs, to the original seed.

Preservation of property rights is important from an efficiency standpoint. A socially suboptimal level of research and development (R\&D) results when property rights are not protected (Arrow; Loury; Novos and Waldman).' Property rights allow firms to obtain short-run economic rents that motivate successful R\&D.

Property right protection of plant genetic material is both a national and an international issue. The International Union for Protection of

LeRoy Hansen is an Economist with the United States Department of Agriculture, Economic Research Service and Mary Knudson is a Research Economist at the University of Michigan.

The authors would like to thank Greg Amacher, John Barton, Steve Crutchfield, Dana Dalrymple, George Frisvold, Stan Liebowitz, Cathy Neumeyer, John Reilly, Ted Schroeder, Peter Swan, and two anonymous reviewers for helpful comments on earlier versions and Rhona Lantin and David Plante for their significant data assistance.

The views expressed are those of the authors and do not necessarily represent those of the United States Department of Agriculture/Economic Research Service or the University of Michigan.

'There are other potential reasons why the private sector's research and development expenditures may not be optimal (e.g., duplicate research activities, monopolies, excess resources spent in copying the new innovation, early release of technology to capture rent, etc. (Dasgupta and Stiglitz; Loury; Swan; Besen and Kirby; Anderson and Hill)) that are not examined here.
New Plant Varieties (UPOV) and the 1970 Plant Variety Protection Act (PVPA) (following standards of UPOV) provide varietal property rights to the parent firm by prohibiting other firms from selling the seed of the protected variety. ${ }^{2}$ The debate on the protection of the PVPA and UPOV centers around farmers' rights to use their harvests as seed.

Some argue that there is no need to eliminate farmer-produced seed because seed firms indirectly capture or appropriate all economic rents through the prices charged for seed of parent varieties. That is, when a variety's harvest can generate economic rents as farmerproduced seed, firms recognize and capture these rents indirectly through charging a high enough price on the parent seed. ${ }^{3}$

Others argue for reducing/eliminating farmers' rights to use their harvest as seed. This group correlates losses in varietal development incentives (economic rents) with use of farmerproduced seed. However, if indirect appropriation exists, then use of farmer-produced seed cannot be correlated with losses in development incentives. As of yet, there has been no empirical test for indirect appropriation perhaps because prices of farmer-produced seed are not observed.

The objective of this study is to provide a workable framework for testing the hypothesis of no indirect appropriation. The framework is applied to the soybean seed industry using crosssectional field-level data on yields, prices, and

\footnotetext{
${ }^{2}$ The United States is a signatory country of UPOV, and therefore must develop property rights following the guidelines of UPOV.

'The indirect appropriation of the value of genetic material is analogous to the indirect appropriation of rents for copyright protected material (Besen and Kirby; Liebowitz; Johnson) and to Alcoa's (possible) indirect appropriation of the value of the aluminum scrap (Swan).
} 
levels of input use. If the hypothesis of no indirect appropriation is rejected, then arguments for increasing the PVPA (and UPOV) limits on farmer-produced seed may not be justified.

\section{Background}

Before the PVPA, there was little restriction on the reproduction of seed from seed crops. New pure-line varieties were developed through public plant breeding programs. These varieties were public goods with farmers or seed firms free to reproduce them or use them in a breeding program.

Since passage of the PVPA, the public sector has decreased real $R \& D$ expenditures in this area; whereas, the private sector has increased its role (Frisvold, Yee, and Day). The seed industry is now a major industry. In 1988, the value of seed planted worldwide exceeded $\$ 51$ billion; expectations are that this value will increase in the future (Kidd).

The significant growth in private sector seed development since passage of the PVPA indirectly indicates success of the Act (Butler and Marion; Perrin, Kunnings, and Ihnen). Until recently, the farmer exemption clause of the PVPA preserved the farmer's right to use his/her harvest as seed as long as revenue from seed sales did not exceed 50 percent of total gross income. A 1995 change in the PVPA allows farmers to use but not sell farmer-produced seed of varieties granted protection under the 1995 change.

Use of farmer-produced seed is significant. Data used in this analysis indicate that nearly 30 percent of the U.S. soybean acres in 1988 and 1989 were planted with farmer-produced seed. Farmer-produced winter wheat seed was used on over 30 percent of the Pacific Northwest and Corn Belt acres and over 70 percent of the Plains states' acres in 1986 and 1987 (Knudson and Hansen).

\section{The Yield-Price Relationship}

Across all major commodities, farmers have many varieties from which to select. Some varieties are recent releases while others have been marketed for several years. Seed companies recognize that farmers, as profit maximizers, pay more for seed of higher-yielding varieties. Higher prices that higher-yielding varieties provide the economic incentive for plant varietal research.

If varieties are competitively priced, then farmers' expected per-acre profits, $\theta$, should not vary across varieties. With direct appropriation, each varietal price, $P(V)$, is set to satisfy:

$$
\mathrm{Y}(\mathrm{V}) * \mathrm{P}_{\mathrm{O}}-\mathrm{P}(\mathrm{V}) * \mathrm{~S}(\mathrm{~V})-\mathrm{KX}=\theta
$$

where $P_{O}$ is the current value expected commodity price; $\mathrm{Y}$ is the expected per-acre yield; $\mathrm{P}$ is the seed price; $\mathrm{S}$ is the per-acre seeding rate; and $K$ and $X$ are unit price and per-acre use rate vectors, respectively, of other inputs. $Y, P$, and $S$ are all functions of seed variety, $\mathrm{V}^{4}$

Differentiating equation (1) with respect to $\mathrm{V}$ generates:

$$
\frac{d Y}{d V} P_{O}=\frac{d P}{d V} S(V)+\frac{d S}{d V} P(V),
$$

where the marginal revenue product associated with the difference in varietal yields equals the difference in varietal costs.

Profit maximization with farmer-produced or bin-run seed expands from equation (1) by including the competitive value of the seed of a variety $V, W(V)$, and its expected yield so that:

$$
\mathrm{Y}^{\mathrm{BR}}(\mathrm{V}) \mathrm{P}_{\mathrm{o}}-\mathrm{W}(\mathrm{V}) \mathrm{S}(\mathrm{V})-\mathrm{KX}=\theta
$$

where $Y^{B R}(V)$ is the expected yield of firstgeneration bin-run seed of variety $\mathrm{V}^{5}$ Other variables are as defined in equation (1). ${ }^{6}$

\footnotetext{
${ }^{4}$ The linear specification of equation (1) does not provide for the effect that a variety may have on use of other inputs. While the specified model is supported by the available data, future research should continue to test more complex yicld specifications.

${ }^{5}$ Impurities in bin-run seed greatly reduce the quality of its harvest as seed. Thus, the harvest of bin-run seed is less competitive as seed. Note that the model can be extended to any number of generations.

${ }^{t}$ One exception is that $K X$ includes cleaning, treating, and storing costs (e.g., the costs of preparing for harvest for next season's seed). These costs are independent of variety, and thus need not be included in W(V) (see Appendix).
} 
Farmers expect $\mathrm{Y}(\mathrm{V})$ to exceed $\mathrm{Y}^{\mathrm{BR}}(\mathrm{V})$ for two reasons. First, real quality differences may exist if large-scale production allows firms to maintain genetic purity, minimize contamination by foreign seed, and ensure high germination. Second, perceived quality differences may exist if farmers feel more confident about the quality of seed from seed firms.

Unless $W(\mathrm{~V})$ exceeds $P_{0}$, it is more profitable to sell the harvest in the commodity market. For varieties where $\mathrm{W}(\mathrm{V})>\mathrm{P}_{\mathrm{O}}$, seed firms indirectly appropriate economic rents by charging the competitive price, $P(V)$, so that:

$$
\mathrm{Y}(\mathrm{V}) * \mathrm{~W}(\mathrm{~V})-\mathrm{P}(\mathrm{V}) * \mathrm{~S}(\mathrm{~V})-\mathrm{KX}=\theta
$$

\section{Testing the Hypothesis of No Indirect Appropriation}

To date, no data on seed price, yield, seeding rate, bin-run yield, and bin-run price are available by variety to allow direct testing of equations (1), (3), and (4). Data are not likely to be available as $W(V)$ is implicit to the farmer who produces his/her own seed. This lack of data eliminates one approach for testing the hypothesis of no indirect appropriation.

However, equations (1), (3), and (4) can be used to construct a yield model to test the hypothesis of no indirect appropriation with farm production data. That is, the relationships associated with direct appropriation are derived based on those of equation (1) so that:

$$
\mathrm{Y}(\mathrm{V})=\frac{\mathrm{S}(\mathrm{V}) * \mathrm{P}(\mathrm{V})}{\mathrm{P}_{\mathrm{O}}}+\frac{(\mathrm{KX}+\theta)}{\mathrm{P}_{\mathrm{O}}}
$$

By simplifying equation (5), yield is written as a function of $\mathrm{SEED}_{\mathrm{D}}$ :

$$
\mathrm{Y}=\beta_{0}+\beta_{1} \mathrm{SEED}_{\mathrm{D}}+\mu_{\mathrm{D}}
$$

where $\beta_{0}$ is an intercept, $\mathrm{SEED}_{\mathrm{D}}$ equals $\mathrm{S} * \mathrm{P} / \mathrm{P}_{\mathrm{O}}$, $\beta_{1}$ is a coefficient expected to equal 1 across varieties where direct appropriation holds, and $\mu_{D}$ is an error term. $\mathrm{Y}, \mathrm{S}$, and $\mathrm{P}$ are the observed yield, seeding rate, and seed price. An important simplification is that the actual variety need not be known.
Similarly, for indirect appropriation. equation (3) is solved for W(V). substituted into equation (4), and simplified so that:

$$
\mathrm{Y}=\beta_{2}+\beta_{3} \mathrm{SEED}_{\mathrm{I}}+\mu_{\mathrm{I}}
$$

where $\beta_{2}$ is an intercept, SEED $D_{1}$ equals $\left[\mathrm{P}^{*} \mathrm{~S}^{2} / \mathrm{P}_{0}\right.$

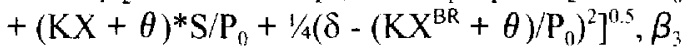
is a coefficient expected to equal 1 when indirect appropriation applies, $\delta$ is the yield decline of first generation bin-run seed, and $\mu_{1}$ is an error term (see the Appendix).

To test the hypothesis of no indirect appropriation, equations (6) and (7) are combined to produce the generalized yield function:

$$
\begin{aligned}
\mathrm{Y} & =\beta_{0}+\beta_{1} \mathrm{SEED}_{\mathrm{D}} *(1-\mathrm{LIM}) \\
& +(1-\mathrm{LIM})_{\mu_{0}}+\beta_{2} \mathrm{LIM} \\
& +\beta_{3} \mathrm{SEED}_{1} * \mathrm{LIM}+\mathrm{LIM} * \mu_{1}
\end{aligned}
$$

where LIM is a qualitative variable that equals 1 for observations on varieties where $\mathrm{W}(\mathrm{V})>\mathrm{P}_{\mathrm{O}}$ and 0 otherwise. LIM is not observed, but when there is indirect appropriation, can be estimated because there will be a $\Gamma$ such that $P * S>\Gamma$ for observations where $\mathrm{LIM}=1$. The value $\Gamma$ (and thus observations where $\mathrm{LIM}=1$ ) is estimated by maximizing the likelihood function of equation (8) across incremental values of $\Gamma$ (Judge et al. (1985) and Goldfeld and Quandt).

Thus, the hypothesis of no indirect appropriation is tested by constraining LIM $=0$ for all observations. That is, the maximum likelihood estimate of equation (8) is tested against the model where LIM is constrained to equal 0 for all observations (no indirect appropriation).

\section{An Application to the Soybean Seed Industry}

This framework is used to test for indirect appropriation by soybean firms. The soybean seed industry is significant - nearly $\$ 0.6$ billion is spent annually for soybean seed in the United States alone (United States Department of Agriculture). The variables of equations (7) and (8) along with other explanatory variables are 
included in the analysis. Variables are listed in Table 1 along with definitions and sources. However, more details on variables and data sources are provided below.

The SEED $_{i}$ variables $(i=D, I)$ are derived from the reported seed price, $P$, and seeding rate, $\mathrm{S}$, of the Cropping Practices Survey (CPS). The May futures price for July soybeans is used as the expected output price, $\mathrm{P}_{\mathrm{O}}{ }^{7}$ The relationships of equations (7) and (8) reflect profit maximization behavior; they are expected to hold across all areas where soybeans are produced. The mean and standard deviation of variables in equations (7) and (8) are given in Table $2 \mathrm{~A}$.

Additional CPS variables as well as variables from three other sources are included in this analysis. The 1988 and 1989 Cropping Practices Surveys (United States Department of Agriculture) identify other farm production practices. The CPS is a random sample of acres in soybean production in major producing states. For this analysis, the 14-state sample is split into Northern (Illinois, Indiana, Iowa, Minnesota, Nebraska, and Ohio) and Southern (Arkansas, Georgia, Kentucky, Louisiana, Mississippi, Missouri, North Carolina, and Tennessee) regions to allow for differences in marginal impacts on yield. ${ }^{8}$ There are 1,669 and 1,244 observations in the Northern and Southern regions, respectively. The CPS identifies the county where an observation is located.

Data on soil and land characteristics are from the National Resource Inventory (NRI) and the associated Soils-5 profile. County-level soil productivity factors are derived for each CPS observation.

Weather data are provided by the National Oceanic and Atmospheric Administration (NOAA) (United States Department of Commerce). Monthly precipitation and temperature data are provided by multi-county weather districts. The Northern observations lie within 53 and the Southern within 43 weather districts. Climate variables are included to serve as proxies for farm production adaptations to expected growing season weather (see Hansen

${ }^{7}$ Derivation of $\mathrm{KX}+\theta$ is provided in the Appendix.

${ }^{8}$ Northern and southern models were estimated separately and little or no change in any of the estimated coefficients were found - including the coefficients on the seed variables. Results are available from the authors. for more on agricultural production estimation across differing climate regimes). In this analysis, climate is measured with 30-year averages of weather.

Given that yield is a function of daylight and daylight is a function of latitude, latitude can serve as a reduced form measure of daylight. Since the CPS does not include observations' latitudes, the mean latitude of the relevant county is used as a proxy (United States Forest Service).

Weather, soil, and other factors affecting yields are included in equation (8) by replacing $\beta_{0}$, the intercept, with:

$$
\begin{aligned}
\alpha_{1} & +\alpha_{2} \text { HMGROWN }_{\mathrm{j}} \\
& +\alpha_{3} \text { IRRIG }_{\mathrm{j}}+\alpha_{4} \text { CORN }_{\mathrm{j}} \\
& +\alpha_{5} \text { SOYBEANS }_{\mathrm{j}}+\alpha_{6} \text { ERODE }_{\mathrm{j}} \\
& +\alpha_{7} \text { LOWTIL }_{\mathrm{j}}+\alpha_{8} \text { NOTILL }_{\mathrm{j}} \\
& +\alpha_{9} \text { LNDCLSS }_{\mathrm{j}}+\alpha_{10} \text { PLDATE }_{\mathrm{j}} \\
& +\alpha_{11} \text { SLPLGTH }_{\mathrm{j}}+\alpha_{12} \text { TFACT }_{\mathrm{j}} \\
& +\alpha_{13} \text { WTRAVG }_{\mathrm{j}}+\alpha_{14} \text { PREJUL }_{\mathrm{j}} \\
& +\alpha_{15} \text { PREJULSQ }_{\mathrm{j}}+\alpha_{16} \text { TMPJUL }_{\mathrm{j}} \\
& +\alpha_{17} \text { TMPAUG }_{\mathrm{j}}+\alpha_{18} \text { PAVGJUL }_{\mathrm{j}} \\
& +\alpha_{19} \text { PAVGJULSQ }_{\mathrm{j}}+\alpha_{20} \text { TAVGJUL }_{\mathrm{j}} \\
& +\alpha_{21} \text { LATIT }_{\mathrm{j}}+\alpha_{22} \text { LATITSQ }_{\mathrm{j}}
\end{aligned}
$$

where the $\alpha_{1}$ is the (new) intercept, and the remaining $\alpha$ 's are the coefficients on the associated variables. Since observations on farmer-produced seed have no seed price or seeding rate variables, a zero-one dummy variable, HMGROWN, is used to approximate the yield affect of the variety of the bin-run seed. The HMGROWN coefficient represents the average value of $\mathrm{PS} / \mathrm{P}_{\mathrm{O}}$ across the bin-run observations. This dummy specification leaves bin-run observations with an error correlated with the actual value of $P S / P_{O}$ (when HMGROWN=1), but independent of other model variables. Thus, estimates of other variables and the hypothesis tests are not affected.

Other zero-one dummy variables are: IRRIG $=1$ when irrigation was used; $C O R N=1$ when corn was the previous a year's crop; 
Table 1. Variable Definitions and Sources

\begin{tabular}{|c|c|c|}
\hline Variable & Definition & Source" \\
\hline YIELD & soybean yield (bu per acre) & CPS \\
\hline $\mathrm{SEED}_{\mathrm{D}}$ & constructed yield-price factor, direct appropriation & CPS \\
\hline $\mathrm{SEED}_{1}$ & constructed yield-price factor, indirect appropriation & CPS \\
\hline HMGROWN & $=1$ if seed used was home grown & CPS \\
\hline IRRIG & $=1$ if the field was irrigated & CPS \\
\hline CORN & $=1$ if corn was grown on field in previous year & CPS \\
\hline SOYBEANS & $=1$ if soybeans were grown on field in previous year & CPS \\
\hline LOWTIL & $=1$ if crop residue covers 30 percent or more of soil surface & CPS \\
\hline NOTILL & $=1$ if there were no tillage since harvest or the previous crop & CPS \\
\hline PLDATE & planting date (numeric day of the year) & CPS \\
\hline ERODE & $\begin{array}{l}=1 \text { if }>50 \text { percent of county farmland is classified as having } \\
\text { a soil erosion problem }\end{array}$ & NRI \\
\hline LNDCLSS & $\begin{array}{l}=1 \text { if }>50 \text { percent of county farmland is classified in class } 1 \text { or } \\
2 \text { (the highest capability classes) }\end{array}$ & NRI \\
\hline SLPLGTH & average slope length (in feet) & NRI \\
\hline TFACT & average soil loss tolerance used in the USLE (tons/acre) & NRI \\
\hline WTRAVG & $\begin{array}{l}\text { the average water-holding capacity of local soils (inches of water } \\
\text { in top foot of soil) }\end{array}$ & NRI \\
\hline PREJUL & actual July precipitation (inches) & NOAA \\
\hline PREJULSQ & PREJUL squared & NOAA \\
\hline TMPJUL & average of actual July daily temperatures ${ }^{\mathrm{b}}\left({ }^{\circ} \mathrm{F}\right)$ & NOAA \\
\hline TMPAUG & average of actual August daily temperatures $\left({ }^{\circ} \mathrm{F}\right)$ & NOAA \\
\hline PAVGJUL & 30-year average of July precipitation (inches) & NOAA \\
\hline PAVGJULSQ & PAVGJUL squared & NOAA \\
\hline TAVGJUL & 30 -year average of July temperature $\left({ }^{\circ} \mathrm{F}\right)$ & NOAA \\
\hline LATIT & estimated latitude of field ( ${ }^{\circ}$ north) & USFS \\
\hline LATITSQ & LATIT squared & USFS \\
\hline Const-shft & shift in the intercept for the south & \\
\hline
\end{tabular}

"CPS = Cropping Practices Survey (United States Department of Agriculture); NRI=National Resources Inventory (United States Department of Agriculture); NOAA = National Oceanic and Atmospheric Administration; USFS = United States Forest Service.

'Reported daily temperature are the average of the high and low temperature of the day. 


\section{Table 2A. Appropriation Test Variables' Means and Standard Deviations Not Region Specified}

\begin{tabular}{lcc}
\hline Variable & Mean & $\begin{array}{c}\text { Standard } \\
\text { Deviation }\end{array}$ \\
\hline YIELD & 24.3 & 12.6 \\
SEED $_{\mathrm{D}}{ }^{\mathrm{a}}$ & 1.50 & 1.17 \\
SEED $_{\mathrm{b}}^{\mathrm{b}}$ & 2.11 & 0.687 \\
SEED $_{\mathrm{b}}^{\mathrm{b}}$ & 47.9 & 4.83 \\
LIM & 0.0106 & 0.103 \\
No. observations & & 2.913 \\
\hline
\end{tabular}

"Mean of $\mathrm{SEED}_{\mathrm{D}}$ in the direct appropriation model derived from observations on purchased seed.

${ }^{b}$ The SEED ${ }_{D}$ and SEED, of the indirect appropriation model. Means and standard deviations are derived from observations where the $\mathrm{SEED}_{\mathrm{i}} \neq 0$.

SOYBEANS $=1$ when soybeans was the previous year's crop; $E R O D E=1$ when over half of the farmland falls into an NRI subclass indicating that erosion is a problem; LOWTIL $=1$ when at least a 30 percent residue cover remained after tillage (see Bull for the methodology applied to residue estimation); NOTILL $=1$ when all crop residue remained on the field surface after planting; and LNDCLSS $=1$ when over half of the farmland is of NRI class I or II. Continuous variables on production and land characteristics are: PLDATE, the planting date (numeric day of year); SLPLGTH, the slope-length (in feet); TFACT, the soil's erosion tolerance (derived for use in the Universal Soil Loss Equation); and WTRAVG, the soil's water-holding capacity. The weather variables are: actual July precipitation, PREJUL; PREJUL squared, PREJULSQ; actual July temperature, TMPJUL; and actual August temperature, TMPAUG. The climate variables are: the 30 -year average of July precipitation as one characterization of climate, PAVGJUL; PAVGJUL squared, PAVGJULSQ; and and the 30-year average of July temperatures, TAVGJUL.' Because the amount of sunlight that plants receive varies by latitude, the approximate latitude of the field, LATIT, and

${ }^{9} \mathrm{~A}$ month's temperature is the average of the day temperatures. Day temperatures are the average of a day's high and low temperature readings specified by region. Their means and standard deviations can be found in Table $2 \mathrm{~B}$.
LATIT squared, LATITSQ, are included as independent variables. Variable definitions can also be found in Table 1 .

The linear relationship in equation (9), with second-degree and interactive terms, is the most common specification of yield functions when data are disaggregated (Houck and Gallagher; Knudson and Hansen; Menz and Pardey; Butell and Naive; Lin and Davenport; Reed and Riggins; Schroder, Headley, and Finley; Sundquist, Menz, and Neumeyer). However, to allow for differences in farming technologies of the north and south, the variables of equation (9) are specified by region. Their means and standard deviations can be found in Table 2B.

The dependent variable, YIELD, in approximately 3 percent of the observations, was truncated at zero as weather (hail, drought, etc.) made harvesting uneconomical. To avoid the truncation bias that Ordinary Least Squares could generate, a tobit model was used (McDonald and Moffitt; Judge et al. (1980)). While other estimation approaches can also generate unbiased results (Heckman 1976, 1979), the tobit approach conserves degrees of freedom and is relevant in a case like this where the independent variables have a continuous effect on yield.

\section{Results}

The tobit estimation results of the direct appropriation model (e.g., LIM=0) and the two-price strategy model are listed in Table 1. estimates have been adjusted for heteroscedasticity following Maddala. ${ }^{10}$

${ }^{10}$ The variables of interest here were not a source of heteroscedasticity. With heteroscedasticity, tobit model estimates may not be efficient or consistent (Maddala and Nelson). Heteroscedasticity was tested for and adjusted by estimating $\delta_{k}^{2}=\left(\tau+\theta Z_{i}\right)^{2}$ where $Z$ is a vector of independent variables, $\theta$ is a vector of coefficients, $\tau$ is the homoscedastic component of the variance, and the $k$ subscript denotes observation $k$ (Rutemiller and Bowers). July temperature, average July temperature squared, and the inverse of the selection probability are significant. The variables adjust for a 3 percent variation in variance. Estimates were made using the Gauss statistical package GRBL. (GRBL is available from Daniel Hellerstein, United States Department of Agriculture/Economic Research Service, 1301 New York Avenue, NW, Washington, DC 20005-4788.) 
Table 2B. Appropriation Test Variables' Means and Standard Deviations Not Region Specified

\begin{tabular}{|c|c|c|c|c|}
\hline \multirow[b]{2}{*}{ Variable } & \multicolumn{2}{|c|}{ North Variables } & \multicolumn{2}{|c|}{ South Variables } \\
\hline & Mean & $\begin{array}{c}\text { Standard } \\
\text { Deviation }\end{array}$ & Mean & $\begin{array}{c}\text { Standard } \\
\text { Deviation }\end{array}$ \\
\hline HMGROWN & 0.292 & 0.455 & 0.317 & 0.465 \\
\hline IRRIG & 0.0461 & 0.210 & 0.125 & 0.330 \\
\hline CORN & 0.640 & 0.480 & 0.194 & 0.395 \\
\hline SOYBEANS & 0.217 & 0.412 & 0.440 & 0.497 \\
\hline ERODE & 0.394 & 0.489 & 0.259 & 0.438 \\
\hline LOWTIL & 0.162 & 0.368 & 0.0105 & 0.102 \\
\hline NOTILL & 0.0389 & 0.194 & 0.0579 & 0.234 \\
\hline LNDCLSS & 0.763 & 0.425 & 0.547 & 0.498 \\
\hline PLDATE & 139.00 & 14.9 & 160.00 & 20.5 \\
\hline SLPLGTH & 210.00 & 120.00 & 197.00 & 83.8 \\
\hline TFACT & 4.53 & 0.491 & 4.49 & 0.441 \\
\hline WTRAVG & 0.211 & 0.0143 & 0.175 & 0.0474 \\
\hline PREJUL & 2.33 & 1.56 & 4.39 & 3.45 \\
\hline PREJULSQ & 7.87 & 10.3 & 31.2 & 35.6 \\
\hline TMPJUL & 76.2 & 1.43 & 79.4 & 1.34 \\
\hline TMPAUG & 74.6 & 3.01 & 79.8 & 1.96 \\
\hline PAVGJUL & 3.89 & 0.313 & 4.61 & 0.875 \\
\hline PAVGJULSQ & 15.2 & 2.38 & 22.0 & 8.83 \\
\hline TAVGJUL & 75.1 & 2.21 & 80.1 & 1.55 \\
\hline LATIT & 41.0 & 9.14 & 34.6 & 1.92 \\
\hline LATITSQ & 1,690 & 168 & 1,200 & 131 \\
\hline No. observations & \multicolumn{2}{|c|}{1,669} & \multicolumn{2}{|c|}{1,244} \\
\hline
\end{tabular}

The reported Pseudo- $R^{2}$ for the model of direct appropriation is 0.297 - about what one expects from cross-sectional data (Table 3)." The Pseudo- $\mathrm{R}^{2}$ of the model of indirect appropriation is 0.325 which suggests that it better explains yield variation. However, a likelihood ratio test is necessary to determine the statistical significance of this difference.

The signs and magnitudes of coefficients on the seed variables are as expected (Table 3 ). Recall that from equations (6) and (7), $\partial Y / \partial S E D_{i}(i=D, I)$ should equal 1 . From the tobit model, a change in $\operatorname{SEED}_{i}(\mathrm{i}=\mathrm{D}, \mathrm{I})$ is given by:

$$
\frac{\partial \mathrm{Y}}{\partial \mathrm{SEED}_{\mathrm{i}}}=\beta_{\mathrm{j}} * \mathrm{~F}(\mathrm{Z})
$$

\footnotetext{
${ }^{11}$ Veall and Zimmerman suggested the Pseudo- ${ }^{2}$ measure because it was found to be the closest to the OLS-R ${ }^{2}$ of the underlying population in Monte Carlo experiments, Compatibility with the OLS- $\mathrm{R}^{2}$ is given priority because the $\mathrm{R}^{2}$ is primarily used to compare models within and across studies.
}

where $F(Z)$ is the cumulative normal probability density function, $Z$ equals $X \alpha$ normalized by the variance, $X$ is a the vector of the independent variables, and $\alpha$ represents the vector of estimated coefficients. If $\partial \mathrm{Y} / \partial \mathrm{SEED}$ equals $1, \beta_{j}$ must equal $1 / F(Z)$. In both models, at the mean value of $Z, 1 / F(Z)$ equals 1.02 . Since 1.02 is within one standard error of each of the estimated $\mathrm{B}_{j}$ 's, results are as expected.

The signs and magnitudes of the other estimated coefficients of equation (9) are consistent with conventional wisdom with the exception of the sign on the coefficient LNDCLSS in the South (Table 3). While the source of this discrepancy is not clear, LNDCLSS is not correlated with SEED $_{\mathrm{D}}$ or SEED $_{l,}$ and thus does not affect coefficient estimates or hypotheses tests related to seed choice. The coefficients $\left(\alpha_{i}{ }^{\prime} s\right)$ and $F(Z)$ in Table 1 allow one to estimate yield changes around mean values of $\mathrm{Z}$ for other independent variables, $\partial \mathrm{Y} / \partial \alpha_{\mathrm{i}}=\alpha_{\mathrm{i}} \mathrm{F}(\mathrm{Z})$.

Additional variables to those specified in equation (9) were tested but none had t-statistics 
Table 3. Tobit Coefficients of Direct and Indirect Appropriation Models

\begin{tabular}{|c|c|c|c|c|}
\hline \multirow[b]{2}{*}{ Variable $^{a}$} & \multicolumn{2}{|c|}{ Direct Appropriation } & \multicolumn{2}{|c|}{ Indirect Appropriation } \\
\hline & Coefficient & $\begin{array}{l}\text { Standard } \\
\text { Error }\end{array}$ & Coefficient & $\begin{array}{l}\text { Standard } \\
\text { Ertor }\end{array}$ \\
\hline$S^{\prime} E E D_{D}$ & $0.734^{* * b}$ & 0.376 & $1.12^{*}$ & 0.413 \\
\hline SEED & & & 1.20 & 0.750 \\
\hline LIM & & -60.7 & 38.4 & \\
\hline HMGROWN $_{\mathrm{N}}$ & 0.806 & 1.06 & 1.63 & 1.12 \\
\hline $\operatorname{IRRIG}_{\mathrm{N}}$ & $8.25^{* *}$ & 1.49 & $8.12^{* *}$ & 1.49 \\
\hline $\operatorname{CORN}_{N}$ & $3.53^{* *}$ & 0.854 & $3.57^{* *}$ & 0.855 \\
\hline SOYBEANS $_{N}$ & -0.104 & 0.963 & -0.0983 & 0.964 \\
\hline ERODE $_{N}$ & $-2.73^{* *}$ & 0.649 & $-2.77 * *$ & 0.648 \\
\hline LOWTIL $_{N}$ & $-2.14^{* *}$ & 0.744 & -2.14 & 0.743 \\
\hline NOTILL $_{N}$ & -1.16 & 1.43 & -1.19 & 1.43 \\
\hline LNDCLSS $_{N}$ & 1.07 & 0.775 & 1.07 & 0.774 \\
\hline PLDATE $_{\mathrm{N}}$ & $-0.105^{* *}$ & 0.213 & $-0.104 * *$ & 0.0213 \\
\hline SLPLGTH $_{N}$ & -0.00354 & 0.00270 & -0.00353 & 0.00270 \\
\hline TFACT $_{N}$ & $4.67^{* *}$ & 0.667 & $4.61^{* *}$ & 0.667 \\
\hline WTRAVG $_{N}$ & $106.00^{* *}$ & 24.3 & $106.00^{* *}$ & 24.3 \\
\hline PREJUL $_{N}$ & $2.48^{* *}$ & $0.97 !$ & $2.48^{* *}$ & 0.971 \\
\hline PREJULSQ $_{N}$ & $-0.466^{* *}$ & 0.128 & $-0.464^{* *}$ & 0.128 \\
\hline TMPJUL $_{N}$ & $-1.80^{* *}$ & 0.441 & $-1.83^{* *}$ & 0.441 \\
\hline TMPAUG $_{N}$ & -1.54 & 0.205 & $-1.53 * *$ & 0.206 \\
\hline PAVGJUL $_{N}$ & 68.7 & 22.9 & $68.5^{* *}$ & 22.9 \\
\hline PAVGJULSQ $_{N}$ & -8.42 & 2.98 & $-8.40^{* *}$ & 2.98 \\
\hline TAVGJUL $_{n}$ & $-1.72^{* *}$ & 0.403 & $1.75 * *$ & 0.403 \\
\hline LATIT $_{\mathrm{N}}$ & -5.29 & 4.53 & -5.71 & 4.54 \\
\hline LATITSQ $_{N}$ & 0.0555 & 0.0540 & 0.0609 & 0.0541 \\
\hline HMGROWN $_{\mathrm{S}}$ & $1.64^{*}$ & 0.987 & $2.24 * *$ & 1.02 \\
\hline IRRIG $_{\mathrm{S}}$ & $5.33^{* *}$ & 1.06 & $5.31^{* *}$ & 1.05 \\
\hline $\mathrm{CORN}_{\mathrm{S}}$ & 0.420 & 1.05 & 0.339 & 1.05 \\
\hline SOYBEANS $_{\mathrm{S}}$ & $-1.29 *$ & 0.963 & $-1.31^{*}$ & 0.784 \\
\hline ERODE $_{\mathrm{S}}$ & $-1.84^{*}$ & 1.04 & $-1.97^{*}$ & 1.04 \\
\hline LOWTIL $_{\mathrm{s}}$ & $-3.11^{* *}$ & 1.50 & $-3.23^{* *}$ & 1.49 \\
\hline NOTILL $_{\mathrm{s}}$ & $-2.77^{* *}$ & 1.19 & $-2.98^{* *}$ & 1.20 \\
\hline LNDCLSS $_{\mathrm{S}}$ & $-1.81^{* *}$ & 0.874 & $-1.85^{* *}$ & 0.875 \\
\hline PLDATE $_{\mathrm{S}}$ & $-0.158 * *$ & 0.0172 & $-0.156^{* *}$ & 0.0172 \\
\hline SLPLGTH $_{\mathrm{s}}$ & 0.00398 & 0.00432 & 0.00416 & 0.00431 \\
\hline TFACT $_{\mathrm{s}}$ & 0.106 & 1.01 & 0.0216 & 1.01 \\
\hline WTRAVG $_{\mathrm{S}}$ & 17.7 & 12.3 & 16.5 & 12.3 \\
\hline PREJUL $_{S}$ & $1.89 * *$ & 0.610 & $1.81^{* *}$ & 0.610 \\
\hline PREJULSQ $_{5}$ & $-0.156^{* *}$ & 0.0486 & $-0.152 * *$ & 0.0485 \\
\hline TMPJUL $_{\mathrm{s}}$ & -0.807 & 0.826 & -0.783 & 0.825 \\
\hline TMPAUG $_{\mathrm{S}}$ & $1.14^{* *}$ & 0.556 & $1.04^{*}$ & 0.557 \\
\hline PAVGJUL $_{\mathrm{s}}$ & $13.7^{* *}$ & 5.82 & $14.3^{* *}$ & 5.83 \\
\hline PAVGJULSQ $_{\mathrm{S}}$ & $-1.27^{* *}$ & 0.549 & $-1.33^{* *}$ & 0.550 \\
\hline TAVGJUL $_{\mathrm{s}}$ & -0.738 & 0.908 & -0.684 & 0.909 \\
\hline LATIT $_{s}$ & $-23.1^{* *}$ & 7.30 & $-23.0^{* *}$ & 7.31 \\
\hline LATITSQ $_{\mathrm{s}}$ & $0.351^{* *}$ & 0.108 & $0.349 * *$ & 0.108 \\
\hline Constant & 101.00 & 118.00 & 108.00 & 118.00 \\
\hline Const-shft & $313.00^{*}$ & 183.00 & $304.00^{*}$ & 184.00 \\
\hline $\mathrm{R}^{2}(\mathrm{MZ})^{\mathrm{c}}$ & & & & \\
\hline$F(Z)^{d}$ & 0.983 & & 0.980 & \\
\hline Variance & & & & \\
\hline
\end{tabular}

${ }^{a}$ The $\mathrm{N}$ and $\mathrm{S}$ subscripts designate variables of the north and south, respectively.

'Single and double asterisks indicate significance at the 90 and 95 percentiles, respectively.

${ }^{c}$ This Pseudo- $R^{2}$ has been suggested by Veall and Zimmerman (1994).

${ }^{\mathrm{d}} F(Z)$ at mean $Z$. Estimation of marginal effects follow from equation (10). 
greater than 1.0 in either region (a conservative cut-off), and hence were subsequently dropped. Variables tested and dropped include: the nitrogen application rate and rate squared; a Soil Conservation Service classification of the land as highly erodible; soil permeability; temperature and precipitation interaction terms; precipitation and temperature variables of other months; and second-degree values of the weather variables.

\section{Hypothesis Test: Applying the Likelihood Ratio Test}

As discussed earlier, the likelihood ratio test can be used to test the hypothesis of no indirect appropriation. Before estimating equation $(8), \beta_{1} \mathrm{SEED}_{D}^{*}$ (1-LIM) is expanded to $\beta_{1} \mathrm{SEED}_{D}$ $\beta_{1}^{*}$ SEED $_{\mathrm{D}}{ }^{*} \mathrm{LIM}$ generating a model of indirect appropriation that nests direct appropriation:

$$
\begin{aligned}
\mathrm{Y}(\mathrm{V}) & =\beta_{0}+\beta_{1} \mathrm{SEED}_{\mathrm{D}}-\beta_{1} \mathrm{SEED}_{\mathrm{D}} \\
& * \mathrm{LIM}+\beta_{2} \mathrm{SEED}_{1} * \mathrm{LIM} \\
& +\beta_{3} \mathrm{LIM}+\mu .
\end{aligned}
$$

Equation (11) is identical to equation (8) when $\beta_{1}^{*}=\beta_{1}$. The constraint $\beta_{1}^{*}=\beta_{1}$ was applied to equation (11); the likelihood function decreased by less than 0.06 which is not significant at any reasonable level of $\chi_{i, \alpha}^{2}$. Furthermore, the constraint caused little, if any, change in the model's coefficients.

The hypothesis of no indirect appropriation is tested by restricting $\beta_{1}^{*}=\beta_{2}=\beta_{3}=0$. This constraint reduces the likelihood function by 3.83 which is significant for $\chi_{3,90}^{2}$. Thus, the hypothesis of no indirect appropriation is rejected at the 90 percent confidence level in favor of the alternative hypothesis that some varietal prices reflect indirect appropriation.

\section{Implications of Indirect Appropriation}

These findings support the hypothesis that seed firms are indirectly appropriating economic rents associated with use of farmer-produced seed. This means that the level of bin-run seed use cannot be made analogous to the seed industry's loss in property rights, at least in soybean production. Thus, farmer-produced or bin-run seed can exist without decreasing incentives for varietal development. Results do not support arguments for the 1995 amendment or any additional reduction in farmers' rights to use their harvest as seed.

If indirect appropriation exists in the sale of soybean seed, it is possible that it can also exist in other pure-line variety seed markets (e.g., wheat). Obviously, the above framework can be applied to test this proposition.

A final note: Model results suggest that approximately 22 percent of all soybean seed will be bin-run while the actual figure is closer to 30 percent. Thus, farmers do not over-produce bin-run seed. The remaining bin-run seed may be pioduced from varieties where $W(V)=P_{O}$, and if some farmers are poor managers, from varieties where $\mathrm{W}(\mathrm{V})<\mathrm{P}_{\mathrm{O}}$.

\section{Summary and Conclusions}

The reproductive capabilities of plants and animals complicate property right protection of genetic materials because the purchaser can reproduce the new genetic line without direct compensation to the developer. The Plant Variety Protection Act (PVPA) explicitly allows farmers to use their harvest as seed without direct compensation to variety developers.

The use of farmer-produced seed has led some to argue that incentives for plant varietal development are reduced because property rights are lost when farmer-produced seed is used. However, others argue that seed producers price the seed of each variety to reflect farmers' highest-valued use of the harvest, and therefore seed firms indirectly appropriate the value of varieties' harvests when used as seed.

The objective of this analysis is to develop a framework for testing the hypothesis of no indirect appropriation and thus provide empirical foundation for this debate. The framework is applied to the soybean industry where the hypothesis of no indirect appropriation is rejected at the 90 percent confidence level. Thus, firms appear to capture the economic rents associated with use of farmer-produced or binrun seed. These results show that no additional property right protection is needed, at least in the soybean industry, where indirect appropriation is 
important as approximately 30 percent of the soybean acres are seeded with bin-run seed.

This empirical evidence of indirect appropriation is critical to the escalating international debate on the level of need for intellectual plant protection. More studies are needed to see how other industries are capturing rents both domestically and internationally. This study is significant as it is the first to offer direct empirical tests to what has been a philosophical debate.

With respect to the 1995 amendment to the farmer exemption clause of the PVPA, bin-run seed can still be used but not marketed. Thus, bin-run seed will continue to be used. If these results hold for other pure-line variety seed grain crops, it is difficult to justify the 1995 amendment or any further restrictions on the useof binrun seed.

When indirect appropriation exists, additional research areas related to efficiency become relevant. Probably most significant is that, with indirect appropriation, incentives for varietal development may or may not equal but could exceed or fall short of incentives that would exist without bin-run seed use (Liebowitz). Answering this question requires an estimate of what seed demands would be without any farmer-produced seed. Other efficiency questions related to the welfare impact of restricting copying and the social welfare loss due to underutilization (Hirshleifer and Riley; Novos and Waldman). There are two dimensions to underutilization: (1) more resources are used to produce the copies than to produce originals; and (2) consumers (in this case, farmers) are willing to pay the marginal cost for the good (seed) but do not obtain the good as price exceeds marginal cost.

[Received November 1994. Final version received December 1995.]

\section{References}

Arrow, K.J. "Economic Welfare and the Allocation of Resources for Invention." The Rate and Direction of Inventive Activity: Economic and Social Factors. Universities-National Bureau Conference Series.
Princeton, NJ: Princeton University Press (for N.B.E.R.), 1962.

Anderson, T.L. and P.J. Hill. "The Race for Property Rights." Journal of Law and Economics 33(April 1990):177-97.

Besen, S.M. and S.N. Kirby. "Private Copying, Appropriability, and Optimal Copying Royalties." Journal of Law and Economics 32(Oct. 1989):255-80.

Bull, L. "Residue and Tillage Systems in 1987 Corn Production," Agricultural Resources Situation and Outlook Report. Washington, DC: United States Department of Agriculture, Economic Research Service, AR-13(1989):36-41.

Butell, R. and J.J. Naive. "Factors Affecting Corn Yields." Washington, DC: Feed Situation, Fds-265, United States Department of Agriculture, 1978, p.14-16.

Butler, L.J. and B.W. Marion. "The Impacts of Patent Protection on the U.S. Seed Industry and Public Plant Breeding." North-Central Regional Research Publication 304, September 1985.

Dasgupta, P. and J. Stiglitz. "Industrial Structure and the Nature of Innovative Activity." The Economic Journal 90(June 1980):266-93.

Frisvold, G., J. Yee and K. Day. "Private and Public Financing of R\&D." Issues For the 1990's, ed. J.B. Stevens, p. 35-36. United States Department of Agriculture, Agriculture Information Bulletin No. 664. 1994, p. $35-36$.

Goldfeld, S, and R. Quandt. "The Estimation of Structural Shifts by Switching Regressions." Annals of Economic and Social Measurement 2,4(Oct. 1973):475-85.

Hansen, L.T. "Farmer Response to Changes in Climate: The Case of Com Production." Journal of Agricultural Economic Research 43,4(Fall 1991):18-25.

Heckman, J.J. "Sample Selection Bias as a Specification Error." Econometrica 47,1(Jan. 1979):153-61.

Heckman, J.J. "The Common Structure of Statistical Models of Truncation, Sample Selection and Limited Dependent Variables and a Simple Estimator for Such Models." Annals of Economic and Social Measurement 5,4(Fall 1976):475-92.

Hirshleifer, J. and J.G. Riley. "The Analytics of Uncertainty and Information - An Expository Survey." Joumal of Economic Literature 17(Dec. 1979):1375-1421.

Houck, J.P. and P.W. Gallagher. "The Price Responsiveness of U.S. Com Yields." American Journal of Agricultural Economics 58(Nov. 1976):731-34.

Johnson, W.R. "The Economics of Copying." The Journal of Political Economy 93,1(Jan./Feb. 1985):158-74. 
Judge, G.G., W.E. Griffiths, R.C. Hill, H. Lütkepohl, and T. Lee. The Theory and Practice of Econometrics,2nd ed. New York, NY: John Wiley and Sons, Inc., 1985.

Judge, G.G., W.E. Griffiths, R.C. Hill, and T. Lee. The Theory and Practice of Econometrics. New York. NY: John Wiley and Sons, Inc., 1980.

Kidd, G.H. "Seed-Delivery System for Plant Biotechnology." Ag. Biotech. 89 Proceedings. Arlington, VA: L. William Teweles and Co, 28-30 March, 1989.

Knudson, M. and L. Hansen. "Investments in Seed Technology: An Examination of Winter Wheat Yield Response to Seed Source." Joumal of Production Agriculture 42,3(Fall 1990):551-57.

Liebowitz, S.J. "Copying and Indirect Appropriability: Photocopying of Journals." Joumal of Political Economy 93,5(Aug./Sept. 1985):945-57.

Lin, W. and G. Davenport. "Analysis of Factors Affecting Corn Yields." Feed Outlook and Situation Report. Washington, DC: United States Department of Agriculture, FdS-285, May 1982, p. 9-14.

Loury, G.C. "Market Structure and Innovation." The Quarterly Joumal of Economics (Aug. 1979):395-410.

Maddala, G. Limited-Dependent and Qualitative Variables in Econometrics. Econometrics Society Publication \#3. New York, NY: Cambridge University Press, 1983.

Maddala, G. and F. Nelson, "Maximum Likelihood Methods for Markets in Disequilibrium." Econometrica 42,6(Nov. 1974): 1013-30.

McDonald, J.F. and R.A. Moffitt. "The Uses of Tobit Analysis." Review of Econometrics and Statistics 62,2(May 1980):318-21.

Menz, K.M. and P. Pardey. "Technology and U.S. Corn Yields: Piateaus and Price Responsiveness." American Journal of Agricultural Economics 62(Aug. 1983):87488.

Novos, I.E. and M. Waldman. "The Effects of Increased Copyright Protection: An Analytic Approach." Journal of Political Economy 92,2(March/April 1984):236-46.

Perrin, R.K., A. Kunnings, and L.A. Ihnen. "Some Effects of the U.S. Plant Variety Protection Act of 1970." Department of Economics and Business Economics Research Report No. 46, North Carolina State University, August 1983.

Reed, M.R. and S.K. Riggins. "Corn Yield Response: A Micro-Analysis." North Central Journal of Agricultural Economics 4,2(July 1982):95-104.

Rutemiller, H.C. and D.A. Bowers. "Estimation in a Heteroscedastic Regression Model." Journal of the
American Statistical Association 63(June 1968):55257.

Schroder, D., J.C. Headley, and R.M. Finley. "The Contribution of Herbicides and Other Technologies to Corn Production in the Corn Belt Region, 1964-1979." North Central Journal of Agricultural Economics: 6,1(Jan. 1984):95-104.

Swan, P.L. "Alcoa: The Influence of Recycling on Monopoly Power." Journal of Political Economy 88,1(Jan./Feb. 1980):76-99.

Sundquist, W.B., K.M. Menz, and C.F. Neumeyer. $A$ Technolog, Assessment of Commercial Corn Production in the United States. Statistical Bulletin No. 546, Agricultural Experiment Station. University of Illinois, 1988.

United States Department of Agriculture. Agricultural Resources Inputs Siluation and Oullook Report. AR-21, February, 1991.

United States Department of Agriculture. Cropping Practices Survey, various years.

United States Department of Commerce, National Oceanic and Atmospheric Administration, National Weather Service, Environmental Data and Information Service. "State, Regional, and National, Monthly and Annual Temperatures Weighted by Area (Jan. 1931 to Dec. 1991)," Historic Climatology Series. September 1992.

United States Forest Service, Wildlife Analytics Group. ZIPFIP: A ZIP and FIPS Database. Miscellaneous Report by Daniel Hellerstein, Daniel McCollum, and Denny Donnelly. Fort Collins, CO, 1990.

Veall, M.R. and K.F. Zimmermann. "Practitioners Corner: Goodness of Fit Measures in the Tobit Model." Oxford Bulletin of Economics and Statistics 56.4(Nov. 1994):485-499.

Washington State Crop Improvement Association, Inc. "Survey Compared Seed Quality." Mimco. October 1986.

\section{Appendix}

Solving equation (3) for W(V), the value of a variety's harvest as bin-run seed, generates:

$$
\mathrm{W}(\mathrm{V})=\frac{\mathrm{Y}^{\mathrm{BR}}(\mathrm{V}) * \mathrm{P}_{0}-\mathrm{KX}^{\mathrm{BR}}-\theta}{\mathrm{S}(\mathrm{V})}
$$

where expected yield, $\mathrm{Y}(\mathrm{V})$; seed price, $\mathrm{P}(\mathrm{V})$; and seeding rate, $S(V)$, are specified by variety, V. Expected profit, $\Theta$; other input costs, $\mathrm{KX}$; and commodity price, $\mathrm{P}_{0}$ are independent of variety. The BR superscripts specify variables for bin-run seed. Substituting equation (A 1 ) into equation (4): 


$$
\begin{aligned}
\mathrm{Y}(\mathrm{V}) & *\left(\frac{\mathrm{Y}^{\mathrm{BR}}(\mathrm{V}) * \mathrm{P}_{0}-\mathrm{KX}^{\mathrm{BR}}-\theta}{\mathrm{S}(\mathrm{V})}\right) \\
& =\mathrm{P}(\mathrm{V}) * \mathrm{~S}(\mathrm{~V})+\mathrm{KX}+\theta .
\end{aligned}
$$

Define $\delta$ as the yield loss of bin-run seed due to loss in seed quality/genetic purity so that $\mathrm{Y}(\mathrm{V})=\mathrm{Y}^{\mathrm{BR}}(\mathrm{V})+\delta$. Equation (A2) becomes:

$$
\begin{aligned}
\mathrm{Y}(\mathrm{V}) *\left(\frac{(\mathrm{Y}(\mathrm{V})-\delta) * \mathrm{P}_{0}-\mathrm{KX}^{\mathrm{BR}}-\theta}{\mathrm{S}(\mathrm{V})}\right) \\
=\mathrm{P}(\mathrm{V}) * \mathrm{~S}(\mathrm{~V})+\mathrm{KX}+\theta
\end{aligned}
$$

Collecting the $\mathrm{Y}(\mathrm{V})$ terms produces:

$$
\begin{aligned}
\mathrm{Y}^{2}(\mathrm{~V}) & +\mathrm{Y}(\mathrm{V}) *\left(\frac{-\delta * \mathrm{P}_{0}-\mathrm{KX}^{\mathrm{BR}}-\theta}{\mathrm{P}_{\mathrm{o}}}\right) \\
& =\left(\frac{\mathrm{P}(\mathrm{V}) * \mathrm{~S}(\mathrm{~V})+\mathrm{KX}+\theta}{\mathrm{P}_{\mathrm{o}}}\right) * \mathrm{~S}(\mathrm{~V}),
\end{aligned}
$$

Solve for $Y(V)$ by adding:

$$
\frac{1}{4}\left(\frac{-\delta * \mathrm{P}_{0}-\mathrm{KX}^{\mathrm{BR}}-\theta}{\mathrm{P}_{\mathrm{o}}}\right)^{2},
$$

to both sides of equation (A4) and taking the square root of both sides to generate:

$$
\begin{aligned}
& \mathrm{Y}(\mathrm{V})=\sqrt{\left(\frac{\mathrm{P}(\mathrm{V}) \mathrm{S}(\mathrm{V})+\mathrm{KX}+\theta}{\mathrm{P}_{\mathrm{o}}}\right) \mathrm{S}(\mathrm{V})} \\
& +\frac{1}{2}\left(\frac{\delta \mathrm{P}_{\mathrm{o}}+\mathrm{KX}^{\mathrm{BR}}+\theta}{\mathrm{P}_{\mathrm{o}}}\right) \text {. }
\end{aligned}
$$

The first right-hand-side term indicares how sced characteristics of varieties priced for indirect appropriation should be specified in a yield function. Thus, SEED, is set equal to this term.

To generate SEED, the variables $P(V), S(V)$, and $P_{0}$ must be observed as in generating $\mathrm{SEED}_{\mathrm{D}}$. However, farmers' expectation of $\mathrm{KX}+\theta$ must also be known. From equation (1), we know farmers expect $\mathrm{Y}(\mathrm{V}) \mathrm{P}_{0}-\mathrm{P}(\mathrm{V}) \mathrm{S}(\mathrm{V})$ (total revenue minus seeding costs) to equal $\mathrm{KX}+\theta$ (other costs plus profits). Thus, an estimate of farmers' expectation of $\mathrm{KX}+\theta$ can be derived using futures (harvest season) prices for the commodity and an average of yield $\left(Y_{A}\right)$, seed price $\left(P_{A}\right)$, and seeding rates $\left(S_{A}\right)$.

Estimates of $Y_{A}, P_{A}$, and $S_{A}$ for the analysis here are listed in Table A. The May futures price of July soybeans is used as an indicator of the expected output price of soybeans, $P_{\mathrm{o}}$

The yield loss of bin-run seed $(\delta)$ is assumed to equal 2 bu/acre based on opinions of those in the industry and the limited empirical evidence that is available. ${ }^{12}$

Table A. Values of $Y_{A}, P_{A}$, and $S_{A}$

\begin{tabular}{lcc}
\hline Variable & North & South \\
\hline $\mathrm{Y}_{\mathrm{A}}$ & 27.3 & 20.2 \\
$\mathrm{P}_{\mathrm{A}}$ & 16.5 & 15.0 \\
$\mathrm{~S}_{\mathrm{A}}$ & 1.03 & 0.898 \\
\hline
\end{tabular}

$Y_{A}$ equals average yield.

$P_{A}$ equals average price farmers paid for new seed.

$S_{A}$ equals seeding rate.

${ }^{12}$ Research shows that bin-run seed yields approximately 1.9 bu/acre less than the parent seed (e.g., $\delta=1.9$ ) (Kip Pendleton, Northrup King Company, personal communication). Knudson and Hansen found yield differences of 1.2 to 6.2 bu per acre between bin-run and purchased seed for winter wheat. 